\title{
MAGMATIC INCLUSIONS IN THE SEARCH FOR NATURAL SILICATE-SALT MELT IMMISCIBILITY: METHODOLOGY AND EXAMPLES
}

\author{
VADIM S. KAMENETSKY ${ }^{1}$, BENEDETTO DE VIVO ${ }^{2}$, VLADIMIR B. NAUMOV ${ }^{3}$, MAYA \\ B. KAMENETSKY ${ }^{1}$, TERRENCE P. MERNAGH ${ }^{4}$, ESME VAN ACHTERBERGH ${ }^{5}$, \\ CHRIS G. RYAN ${ }^{5}$, PAUL DAVIDSON ${ }^{1}$ \\ ${ }^{1}$ School of Earth Sciences and Centre for Ore Deposit Research, University of \\ Tasmania, Hobart, Australia \\ ${ }^{2}$ Dip. Di Geofisica e Vulcanologia, Università di Napoli "Federico II", Napoli, Italy \\ ${ }^{3}$ Vernadsky Institute of Geochemistry, Russian Acad. of Sciences, Moscow, Russia \\ ${ }^{4}$ Geoscience Australia, Canberra, ACT, Australia \\ ${ }^{5}$ CSIRO Exploration and Mining, North Ryde, NSW, Australia
}

\begin{abstract}
Immiscible phase separation during the cooling and crystallisation of magmas is an inherently fugitive phenomenon and melt inclusions may provide the only remaining evidence of this process. We detail those features of such inclusions that can both prove the existence of immiscible phase separation, and constrain the compositional signature of the process. To do so requires the combination of traditional methods (petrographic examination, microthermometry, etc.) with state of the art microbeam analytical techniques (laser Raman spectroscopy and proton-induced X-ray emission). Examples of inclusions in phenocrysts from barren and mineralised rocks are provided to illustrate the approach and validate the interpretations.
\end{abstract}

\section{INTRODUCTION}

The most perplexing question concerning transition from magmas to hydrothermal fluids is the nature of the phases (melts, vapour- or liquid-rich fluids) that derive from magmas at the brink of solidification. It is widely believed (e.g., orthomagmatic model) that the phases exsolved late in the crystallisation of aluminosilicate magmas carry important amounts of volatile (e.g., $\mathrm{H}_{2} \mathrm{O}, \mathrm{CO}_{2}, \mathrm{Cl}, \mathrm{S}, \mathrm{F}$ ) and metallic elements that may subsequently enter hydrothermal systems and be responsible for formation of certain types of ore deposits (e.g., W-Sn skarns and greisens, pegmatites, and $\mathrm{Cu}-\mathrm{Mo}-\mathrm{Au}$ porphyries). Clearly underlying this thinking is the notion that the peculiar chemistry of the near-solidus magmatic fluids $\left(\mathrm{CO}_{2}\right.$ - and $\mathrm{H}_{2} \mathrm{O}$-rich) or melts (essentially non-silicate - usually $\mathrm{H}_{2} \mathrm{O}$-bearing chloride, carbonate, sulphate, and phosphate, hereafter "salt melt", and sulphide-rich liquids) is related to the process of unmixing or direct immiscibility with parental aluminosilicate magmas.

Leaving aside the question of how magma-derived melts and fluids ultimately evolve into potentially ore-forming solutions, there are immediate problems about physical state and chemical compositions of these transitional phases. They appear to be released from solidifying magma in a murky window of temperatures between 750 and $<500^{\circ} \mathrm{C}$, 
which remains largely uncovered by the geological research. The reason for this is twofold:

1. Historically, igneous petrology was segregated from studies into hydrothermal systems, although some overlap in the form of experimental and theoretical studies was always present;

2. Fluid and melt phases that could have been representative of natural compositions, leave virtually no record, as they are completely exhausted by crystallisation and degassing.

The second problem can be partially resolved by using melt and fluid inclusion studies for samples representative of magmatic-hydrothermal transition (see reviews in Roedder, 1992; De Vivo and Frezzotti, 1994; Lowenstern, 1995; Frezzotti, 2001). These are not necessarily intrusive or volcanic rocks that host mineralisation or bear hydrothermal alteration. In theory and in practice, any magma that is saturated in volatiles can further evolve by losing volatiles during degassing or separation of immiscible volatile-rich melts. At this point silicate melts and their immiscible volatilerich products coexist and can be preserved if trapped as inclusions by crystallising minerals (e.g., Roedder and Coombs, 1967; Reyf and Bazheyev, 1977; Harris, 1986; Naumov et al., 1990; Lowenstern et al., 1991; Solovova et al., 1991; Frezzotti, 1992; Solovova et al., 1992; De Vivo et al., 1993; Lowenstern, 1993; Yang and Bodnar, 1994; De Vivo et al., 1995; Reyf, 1997; Kamenetsky et al., 1999; Thomas et al., 2000; Davidson and Kamenetsky, 2001; Fulignati et al., 2001). Such inclusions are still magmatic in nature but their compositions are much closer to hydrothermal solutions as potentially ore-forming elements preferentially partition into late magmatic immiscible phases ( e.g., Candela and Holland, 1984; Shinohara, 1994; Webster, 1997).

However, in recent years the melt and fluid inclusion approach has become more attractive to growing numbers of researchers. Although there still remain limitations related to whether inclusions represent natural melts and fluids or to post-entrapment modification, the application of modern analytical tools to inclusions (FTIR and Raman spectroscopy, electron, ion and proton microprobes, scanning electron microscopy, laser ablation ICPMS etc) provides great advantages over conventional methods.

The aims of this paper are: 1) to describe unequivocal occurrences of late magmatic immiscibility using melt and fluid inclusions in phenocrysts from mineralised and unmineralised rock suites; 2) to recommend a set of methods and techniques that are most efficient in looking into magmatic-hydrothermal transition. Our test study covers inclusions in different minerals - quartz, clinopyroxene, leucite, and K-feldspar that crystallised from compositionally diverse magmas in different tectonic environments. Two of our examples represent clear association with economic mineralisation - Balut Dyke, Dinkidi Cu-Au porphyry deposit, Philippines (Kamenetsky et al., 1999) and Omsukchan Sn-granite, NE Russia (Naumov and Sokolov, 1981; Kamenetsky et al., 2002b), whereas in the other two examples (mafic to felsic xenoliths in alkaline lavas from Ventotene Island, Italy (De Vivo and Frezzotti, 1994; De Vivo et al., 1995) and dacite-rhyolite lavas from the 1.6 Ga Gawler Craton, S Australia (Kamenetsky et al., 2000)) this association is either hypothetical (so far) or does not exist. 


\section{METHODOLOGY FOR STUDYING MAGMATIC IMMISCIBILITY}

\section{Optical examination of inclusions}

Optical examination at room temperature of phases present among magmatic inclusions is a prerequisite to and a keystone in the immiscibility studies.

Sample preparation: Samples can be prepared as double side polished sections on a soluble glue, with thickness comparable to the size of phenocrysts in order to preserve large inclusions intact. Whole rock sections are particularly useful for observing distribution of inclusions within a single crystal and constraining relationships (e.g., temporal) between different types or generations of inclusions. Double side polishing and the use of soluble glue are required if phenocrysts from a section are to be further

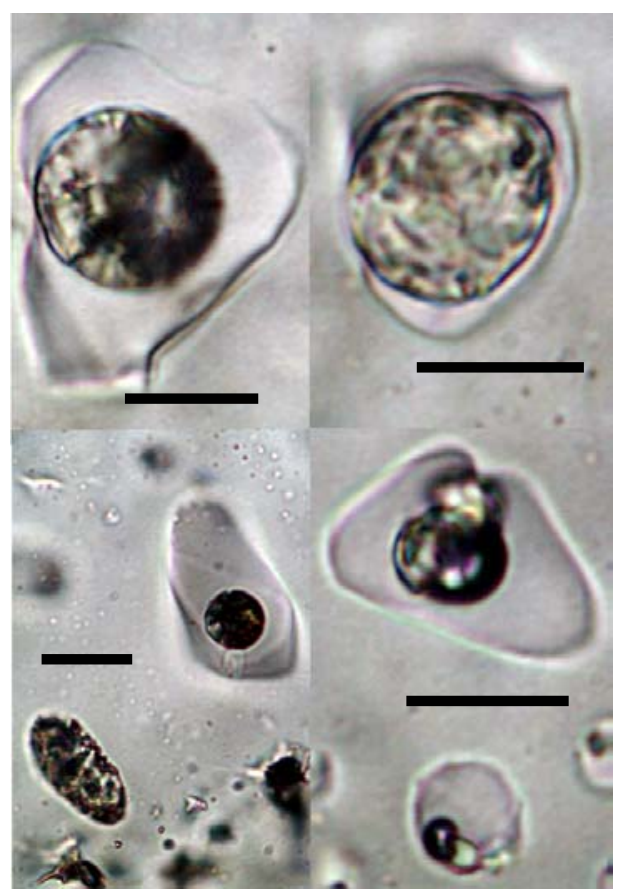

Fig. 1. Variable ratios between felsic glass and non-silicate globules in melt inclusions trapped in quartz from a granitic clast in a Gawler Range rhyolite. Scale bars are $10 \mu \mathrm{m}$. used for experimental and analytical studies. If a rock is sparsely porphyric we recommend picking phenocrysts or their fragments from a crushed and sieved rock, followed by mounting grains in epoxy. Note that a few hundred grains can be placed in a standard mount, and this allows much broader examination of inclusions. Grains of interest can be later picked up from epoxy (with a hot needle), polished and studied individually.

Sample description: The task of finding and photographing inclusions under petrographic microscope, although laborious and time consuming, should be performed on as many phenocrysts as possible. It is important to identify temporal populations of inclusions and their genetic relationships. The criteria for recognising primary, pseudosecondary and secondary inclusions are widely discussed in the literature (e.g., Roedder, 1979). For immiscibility studies the inclusions of primary and pseudosecondary origin (i.e., those trapped during the phenocrysts crystallisation) are a principal target as they characterise the magmatic phases. However, 


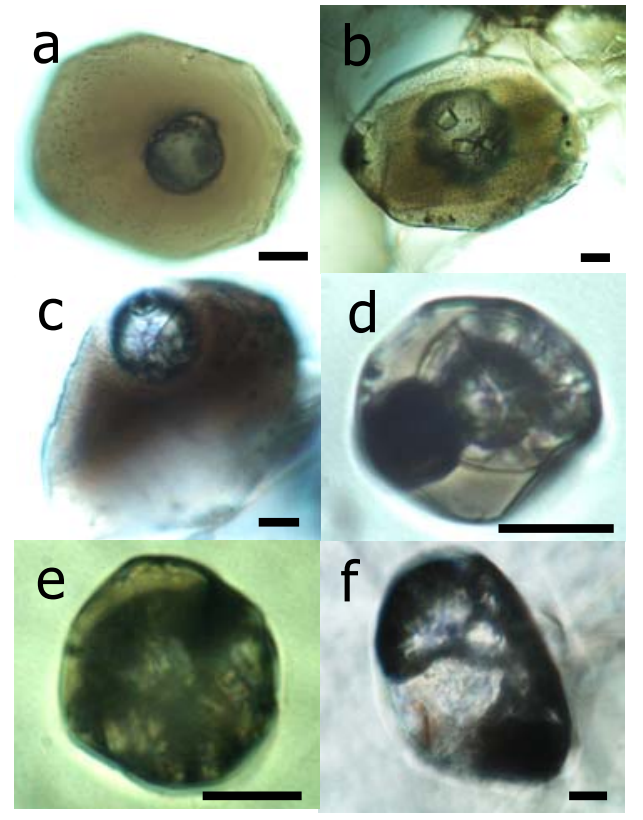

Fig. 2. Photomicrographs of melt inclusions in clinopyroxene from the Ventotene mafic xenolith showing variable proportion of silicate melt and volatile-rich, essentially non-silicate phases (see text for details). Scale bars are $10 \mu \mathrm{m}$. secondary inclusions trapped in magmatic phenocrysts are not to be ignored if they may represent melts and fluids at temperatures just below the solidus of silicate magmas (Prokofiev et al., 1999).

To recognise magmatic immiscibility using inclusions a simple but stringent test was proposed by Edwin Roedder (1979). This test is to look for inclusions with variable amounts of two or more supposedly unmixed but coexisting phases. Commonly one or several phases in such inclusions have spherical shapes. As an example we refer to Fig. 1, which shows microphotographs of melt inclusions coexisting in a cluster in quartz from a granite xenolith in a Gawler Range rhyolite. Note the variable proportions of clear felsic glass and vapour-rich globules of essentially non-silicate phases represented by various carbon species $\left(\mathrm{CO}_{2}\right.$, carbonates and amorphous carbon). Another example is provided by inclusions in clinopyroxene from Ventotene xenoliths, shown in Fig. 2. In this case in the coexisting inclusions variable amounts of co-trapped brownish silicate glass (formerly melt), vapour \pm crystal globules and sometimes $\mathrm{Cu}$-rich, Fe-sulphide globule (Fig. 2d) can be seen. The proportion of glass in these inclusion ranges from $>95 \mathrm{vol} \%$ (Fig. 2a) to $<5$ vol\% (Fig. 2e). Glass-free inclusions are also present (Fig. 2f). Vapourrich globules are also variable in terms of amount of crystals present. This amount varies from a few minute crystals decorating the walls (Fig. 2a) through large discrete euhedral crystals (Fig. 2b) to crystalline masses occupying the entire volume of the globules (Fig. 2 c-e).

However, in practical studies a researcher should be aware of the fact that inclusions of homogeneous melt or fluid may be trapped at temperatures above immiscibility, and unmixing may happen in such inclusions during cooling. If this is the case inclusions should show roughly the same proportions of in situ formed immiscible phases. This is best illustrated by numerous melt inclusions in leucite from Ventotene xenoliths (Fig. 3 ). Despite variable size these inclusions show approximately similar ratios of brownish 
alkaline silicate glass, translucent crystalline mass of chlorides, carbonates, and sulphates (according to Raman spectroscopy; see below) and $\mathrm{Cu}$-enriched Fe-sulphide globule usually on the meniscus between silicate and non-silicate melts.
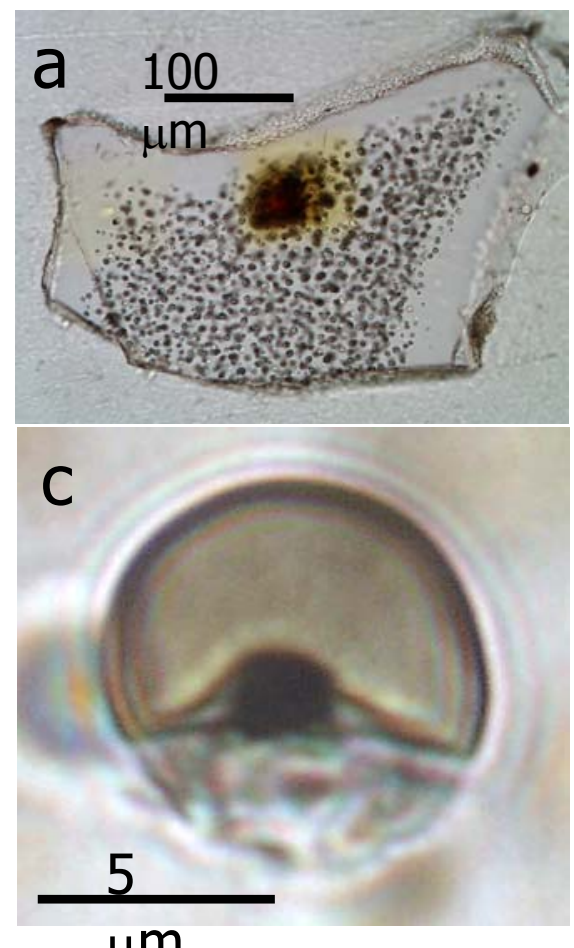

$\mu \mathrm{m}$

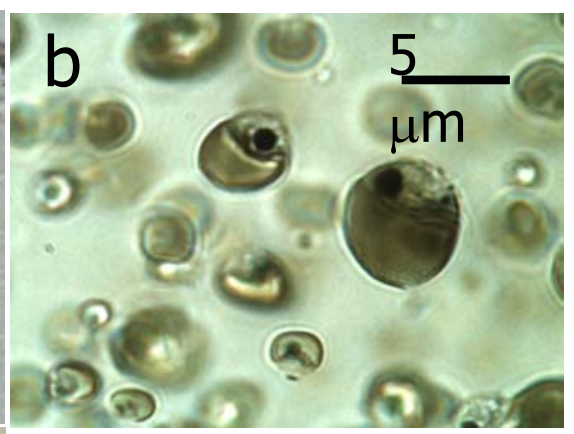

Fig. 3. Melt inclusions in the core of leucite crystal from Ventotene mafic xenoliths (a) comprising silicate glass, carbonate-sulphate-chloride aggregate and sulphide globule $(\mathbf{b}, \mathbf{c})$. Relatively constant proportions of these phases in melt inclusions argue for in situ immiscibility.

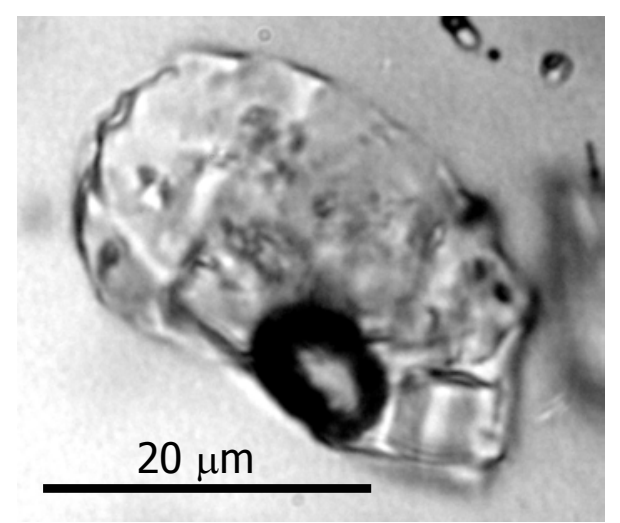

Fig. 4. Cubic salt mineral (halite ?) associated with a fluid phase in the silicate melt inclusion in quartz from the Omsukchan granite. 
A researcher should be always on the lookout for non-silicate phases (such as salt crystals, $\mathrm{CO}_{2}$ and $\mathrm{H}_{2} \mathrm{O}$ vapours and liquids, sulphide globules, etc) in otherwise normal silicate melt inclusions. Occurrences of this phenomenon have been noted frequently in different magmatic suites (e.g., Roedder and Coombs, 1967; Lowenstern et al., 1991; Solovova et al., 1991; Tsareva et al., 1991; Andreyeva et al., 1995; Yang and Scott, 1996; Davidson and Kamenetsky, 2001; Kamenetsky et al., 2001; Kamenetsky et al., 2002a), and our Fig. 4 illustrates the presence of a cubic mineral (halite?) in a crystalline felsic melt inclusion from the Omsukchan granite.

Sometimes Roedder's test is not easy to exercise, especially at room temperature or prior to heating of melt inclusions in phenocrysts from slowly cooled rocks, because post-entrapment crystallisation may mask heterogeneously trapped immiscible phases within inclusions. To overcome this problem we recommend the use of heating and quenching techniques.

\section{Thermometric experiments with inclusions}

Aims: A lot of details of thermometric experiments with melt inclusions are available in the modern literature. In our immiscibility studies we use heating and subsequent quenching to pursue the following objectives:

1. Convert crystalline silicate daughter phases within devitrified inclusions into melt, and quench this melt into homogeneous glass. This makes heterogeneously trapped phases (including non-silicate, if present) available for observation and analysis;

2. Liberate immiscible salt melt and fluid phases heterogeneously trapped with the silicate melt and promote their coalescence into larger formations (globules or bubble) in order to successfully analyse them using microbeam techniques;

3. Initiate silicate melt - salt melt immiscibility within silicate melt inclusions that were trapped homogeneously and quenched in nature at temperatures above the temperature of immiscibility. The task is to exsolve non-silicate phases large enough for observation and subsequent analysis;

4. Observe and document (e.g., photographing or video recording) the behaviour (e.g., melting, homogenisation, crystallisation etc) inside immiscible non-silicate globules irrespectable of whether they were heterogeneously trapped or exsolved during heating.

Experimental techniques: Different heating stages and optical microscopes are available for this kind of work and various heating techniques are employed in practice. There are no generally accepted preferences as to the choice of heating setup or heating rate. In fact, every sample and every inclusion should be treated individually, and the alternating of heating and cooling in initiating in situ immiscibility must be applied wisely to achieve desirable results. In our studies we use a Linkam TS1500 heating stage with TMS 94 temperature control unit and an Olympus BX51 microscope. To prevent oxidation of Fe-bearing minerals at high temperatures we recommend maintaining an inert atmosphere inside the heating stage using high purity argon.

The laborious work with individual grains on a heating stage can be relieved if quantities of inclusion-bearing grains (e.g., >100) are first bulk heated in a furnace and 


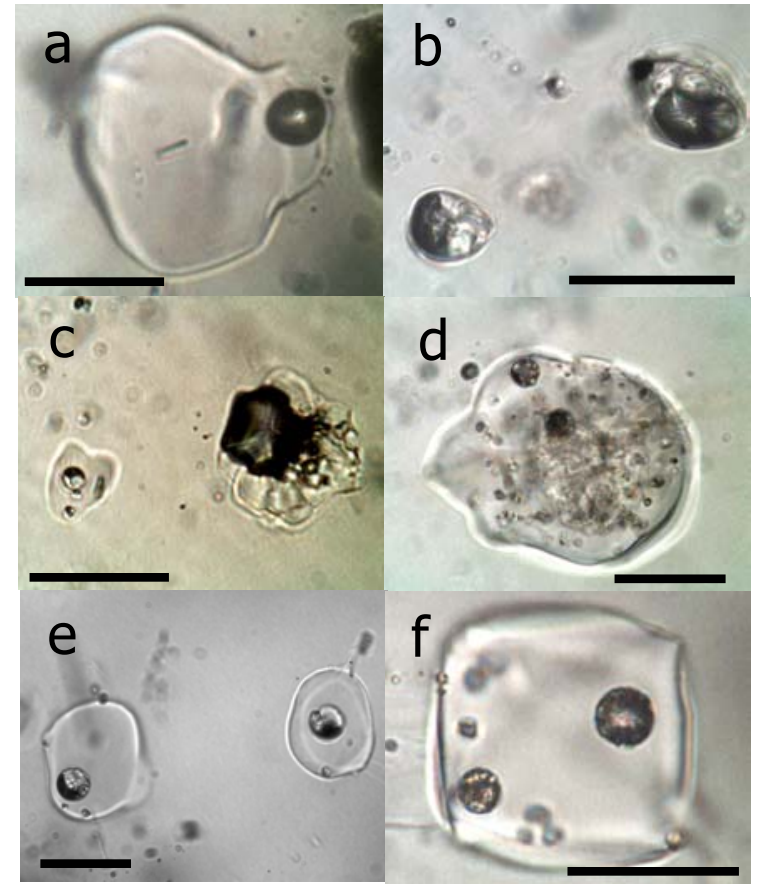

Fig. 5. Photomicrographs of heated and quenched melt inclusions in quartz from the Omsukchan granite (a-e) and the Gawler Craton rhyolite (f) showing variable amounts of silicate glass and volatile- and salt-rich phases. The immiscible endmembers are shown on Fig. 5a (silicate glass inclusion with shrinkage vapour bubble) and Fig. 5b (salt melt inclusions). Note microemulsion textures formed by globules of salt melt (d, f). Scale bars are $20 \mu \mathrm{m}$. then quenched. The first aim of bulk heating is to convert the silicate content of inclusions into glass and initiate silicate-salt immiscibility that can be later enhanced and recorded properly in a heating stage with visual control. The second aim that a researcher may keep in mind is to provide plentiful samples for different microbeam analysis. Another aim is to identify those inclusions that have been already compromised (e.g., fractured) or decrepitated during bulk heating. This applies to inclusions in the vicinity of crystal deformations or invisible cracks and inclusions hosted by minerals with strong cleavage (e.g., plagioclase, clinopyroxene etc). A great number of inclusions in quartz cannot survive temperature-related volume change of host quartz $(\alpha$ to $\beta$ quartz transition at $\sim 573^{\circ} \mathrm{C}$ ) and appear decrepitated after first heating. The appropriate combination of

temperature and heating times in these preliminary experiments is to be derived from a series of heating runs on a few grains from each sample.

The bulk heating experiments are most suitable for those samples that record silicate-salt melt immiscibility that happened in a magma chamber during natural cooling. In this case the post-heating examination should reveal variable proportions of silicate glass and salt globules in a single inclusions. Commonly large numbers of inclusions may still represent homogeneous trapping of silicate or salt melt "endmembers" (Fig. 5 a, b). However, in such samples with inclusions representing both end-member compositions, the "mixed" varieties (Fig. 5 c-f) should also be 
present, and actually these are vital if the immiscibility is to be proved (Roedder, 1979). Microemulsion texture in melt inclusions is also a good evidence for heterogeneous trapping of immiscible salt melt phases with the silicate melt (Fig. 5 d, f).

Silicate melt - salt melt immiscibility that may occur in homogeneously trapped silicate melt inclusions after entrapment during natural cooling, or during heating experiments with no visual controls can be distinguish from heterogeneous trapping by examining relative proportions of both silicate and salt phases. For example, after heating and quenching two coexisting inclusions from the Omsukchan granitic quartz (Fig. 5e) unlike other inclusions in this sample (Fig. 5) show a single, relatively small $(\sim 3.5 \mathrm{vol} \%)$ salt melt globule. These can be tentatively interpreted as exsolved from a silicate melt after entrapment. In another example from the Gawler Range rhyolite exceptionally rare occurrence of salt globules in glass (two coexisting inclusions in only one quartz grain out of several hundred heated grains) may suggest that immiscibility occurred during the experimental run (Fig. 5f).

Despite very short experimental times compared to the timescales of geological processes, in situ immiscibility within a given homogeneously trapped melt inclusions is still feasible. A few examples confirming this are given in recent literature. Thomas et al. (2000) reported the occurrence of immiscibility between two silicate melts with different concentration of volatiles in a single melt inclusion in the Ehrenfriedersdorf pegmatite quartz after quenching from $617^{\circ} \mathrm{C}$. Experimental heating and cooling of melt inclusions in the Mt Vesuvius endoskarn minerals has revealed that unmixing and homogenisation between carbonate and chloride melts in a single inclusion could be repeatedly attained at $\sim 690^{\circ} \mathrm{C}$ (Fulignati et al., 2001).

Heating stage experiments: Heating stage experiments with visual control are a prerequisite for the study of in situ separation of immiscible phases within a given inclusion and phase transformations (e.g., melting and crystallisation) within immiscible phases.

Figure 6 shows heating of salt melt immiscible globules trapped together with silicate melt in the Omsukchan granitic quartz. This originally devitrified inclusion was first heated in the furnace for $20 \mathrm{hrs}$ at $950^{\circ} \mathrm{C}$. After quenching, the silicate content formed a clear glass containing two large and a few smaller salt melt globules. Several subsequent heating experiments show that 1) salt globules remain constant in size, do not change their position with respect to silicate melt, and do not mix with silicate melt even at temperatures exceeding liquidus $\left(900-1100^{\circ} \mathrm{C}\right)$; 2) first melting in salt globules happens at $150-190^{\circ} \mathrm{C} ; 3$ ) vapour and solid phases in salt globules acquire spherical and pseudocubic shapes, respectively, and decrease in size with further heating and melting; 4) the last solid phase melts at $\sim 735^{\circ} \mathrm{C}$; and 5) complete homogenisation within the salt globules (vapour bubble dissolution) happens at $\sim 840^{\circ} \mathrm{C}$. Note that the above phase transformations take place simultaneously in all entrapped globules, and also in salt melt inclusions (alike those on Fig. 5b) outside this composite inclusion. In this example silicate and salt components of the inclusion show no significant interaction with each other and their miscibility is not achievable at the conditions of experiment.

A different picture is observed in experiments with melt inclusions in K-feldspar from the Ventotene felsic xenolith. At room temperature two adjacent inclusions have 


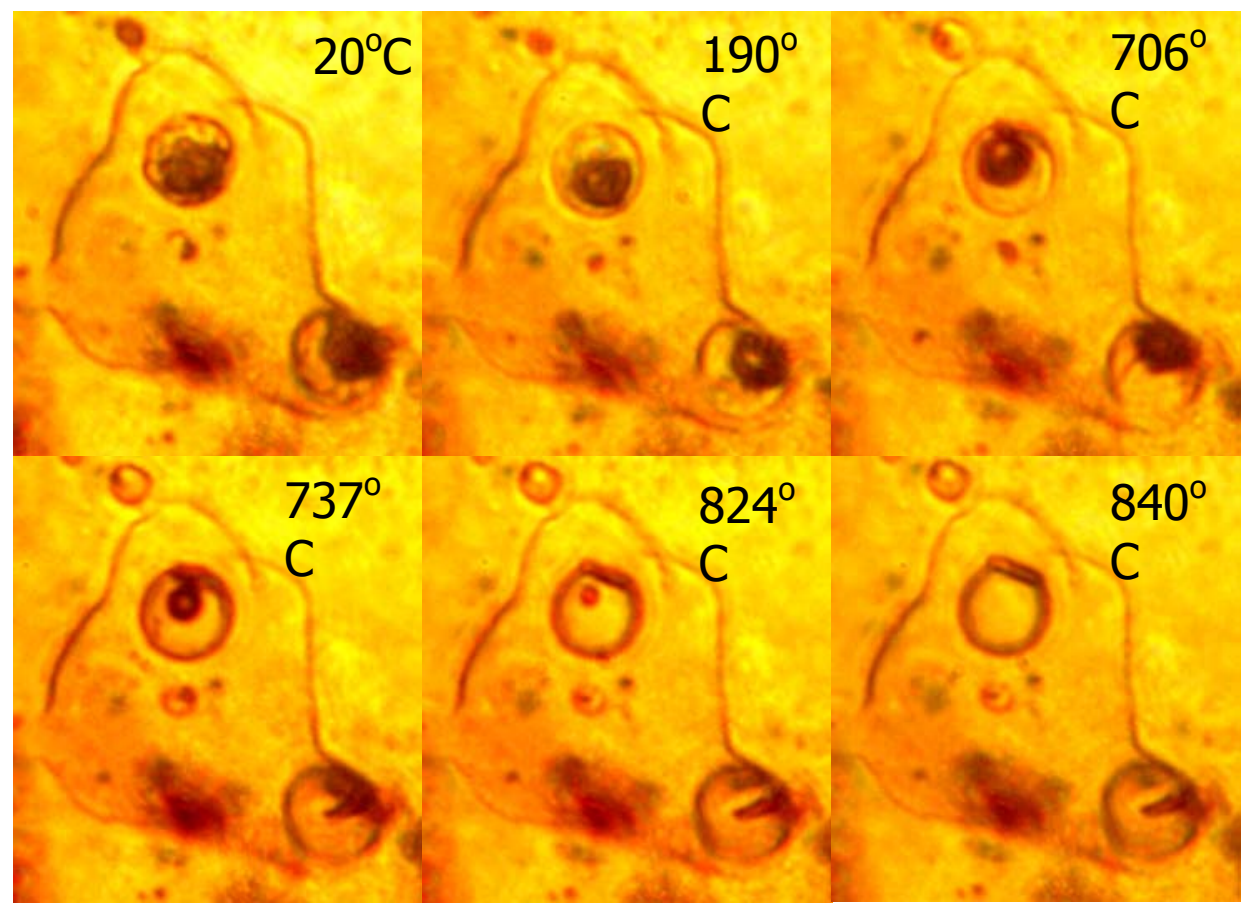

Fig. 6. Melting and homogenisation during heating in the immiscible salt globules within a silicate melt inclusion hosted by quartz from the Omsukchan granite. Size of globules is $\sim 12 \mu \mathrm{m}$.

rectangular shape and consist of crystalline phases and deformed vapour bubble (Fig. 7a). First melting, as evident from enhanced crystal boundaries, occurs at temperatures as low as $300-400^{\circ} \mathrm{C}$. This suggests that daughter crystal belong to non-silicate species, and thus these inclusions can be classified as salt melts. Complete melting of daughter phases is achieved at $605-635^{\circ} \mathrm{C}$, whereas the shape of inclusions becomes more round. The smoothness of shape and reduction in size of a bubble-bearing liquid are clearly noticeable at $\sim 850^{\circ} \mathrm{C}$. Close to this temperature a phase other than salt melt shows up outlining the original contours of the inclusions. With further transformation of a bubble-bearing melt phase into almost spherical globule at $>900^{\circ} \mathrm{C}$ the presence of this phase (presumably silicate melt) is unambiguous. The bubbles in salt globules homogenised at 841 and $857^{\circ} \mathrm{C}$ on first heating, and at 919 and $938^{\circ} \mathrm{C}$ on second heating. Cooling below $850^{\circ} \mathrm{C}$ obscures the phase boundary between silicate and salt melt, causes spontaneous crystallisation of non-silicate crystals at $\sim 400^{\circ} \mathrm{C}$, and returns a rectangular shape to these inclusions.

Heating/cooling of the same inclusions in the third consecutive run caused simultaneous nucleation of bubbles in both silicate and salt liquids of the lower inclusion at $930^{\circ} \mathrm{C}$, then the coalescence of bubbles in the silicate melt at $902^{\circ} \mathrm{C}$, and 


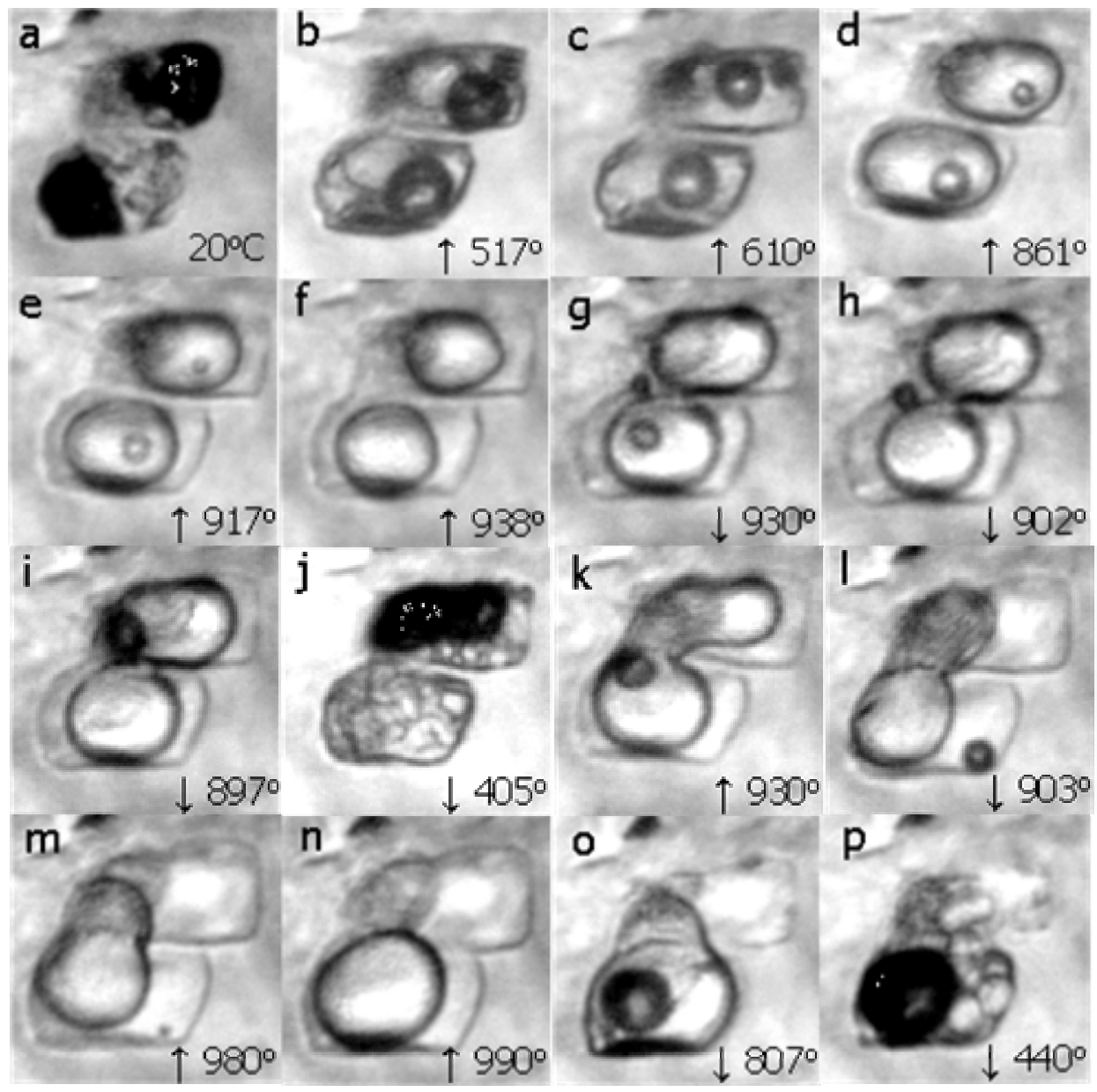

Fig. 7. Phase transformations (melting, immiscibility, crystallisation, homogenisation etc) during heating and cooling of two silicate-salt melt inclusions in K-feldspar from the Ventotene felsic xenolith. See text for details. Upwards and downwards arrows indicate heating and cooling events, respectively. Size of inclusions is $\sim 25 \mu \mathrm{m}$.

migration of the bubble into the salt globule of the upper inclusion at $897^{\circ} \mathrm{C}$ (Fig. $7 \mathrm{i}$ ). In this run a neck formed bridging between two inclusions possibly as a result of melting through the host feldspar. In a series of repeated experiments the salt melt content of the upper inclusion poured progressively into the lower inclusion, and eventually one large salt globule containing a vapour bubble formed (Fig. 7 n-p).

While most silicate-salt melt inclusions in the Ventotene feldspar show behaviour as described above due to very low silicate melt/ salt melt ratio, in some cases silicate melt prevails in composite inclusions, and thus the salt melt occurs in a spherical globule at room temperature (Fig. 8). 


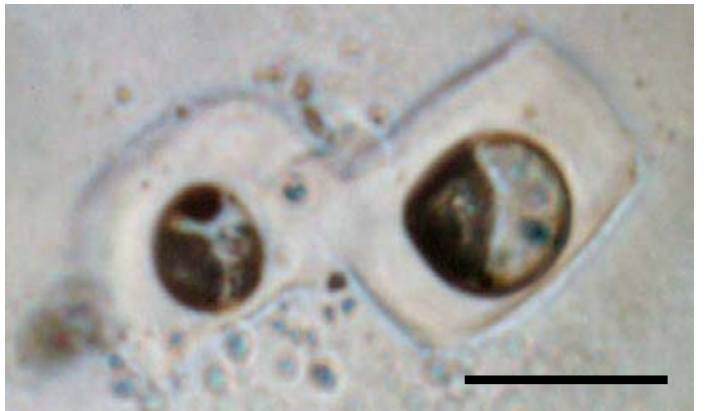

Fig. 8. Heated and quenched melt inclusions in K-feldspar from the Ventotene felsic xenolith showing separation of immiscible salt globule from the silicate melt (glass). Opaque rounded phase in salt globules is another immiscible phase represented by $\mathrm{Cu}$-rich sulphide (see Fig. 10). Scale bar is 20 $\mu \mathrm{m}$.

\section{PHASE AND CHEMICAL COMPOSITIONS: ANALYTICAL TECHNIQUES}

Once immiscible phases are recognised as individual inclusions or in composite inclusions the identification of their mineral constituents and bulk chemical composition is necessary. One endmember of the immiscibility - a silicate melt is usually quenchable into homogeneous glass that can be exposed by polishing and analysed by conventional microbeam techniques (e.g., electron microprobe, laser ablation ICPMS). Silica-poor and non-silicate, salt melts do not form glass even at very high quenching rates because of their extremely low viscosity. Consequently, at room temperatures these melts are represented by aggregates of crystals, a large volume vapour bubble(s) and possibly interstitial aqueous solution. The main problem in exposing such melt for analysis is in that some daughter minerals are unstable in the air or react with atmospheric moisture, and that aqueous and gaseous components are likely to be lost. The heterogeneous state of salt melt inclusions at room temperature poses a problem in calculating their bulk composition. Below we present a few suggestions as to how these problems are partially overcome in our studies.

\section{Energy-and wavelength X-ray dispersive analysis (EDS and WDS)}

The lapidary work is the most critical stage during the preparation of salt melt inclusions for the electron microprobe analysis. Grains with inclusion of interest should be ground individually by hand on very fine $\mathrm{SiC}$ abrasive paper, and the use of water must be avoided. Kerosene or any other light oil lubricant serves well, and once the inclusion is very close to the surface $(<$ several microns) further grinding and ultimate polishing is done with $1 \mu \mathrm{m}$ diamond oil-based polishing paste on slowly rotating artificial silk disk such as Lamplan 450. The surface with exposed inclusion is cleaned with petroleum-based solvents like shellite, and the sample is immediately carbon (or gold)-coated and stored in a desiccator. Chemical composition of daughter minerals in exposed inclusions is then analysed routinely using an electron microprobe or scanning electron microscope equipped with the EDS or WDS detectors. For example, Fig. 9 


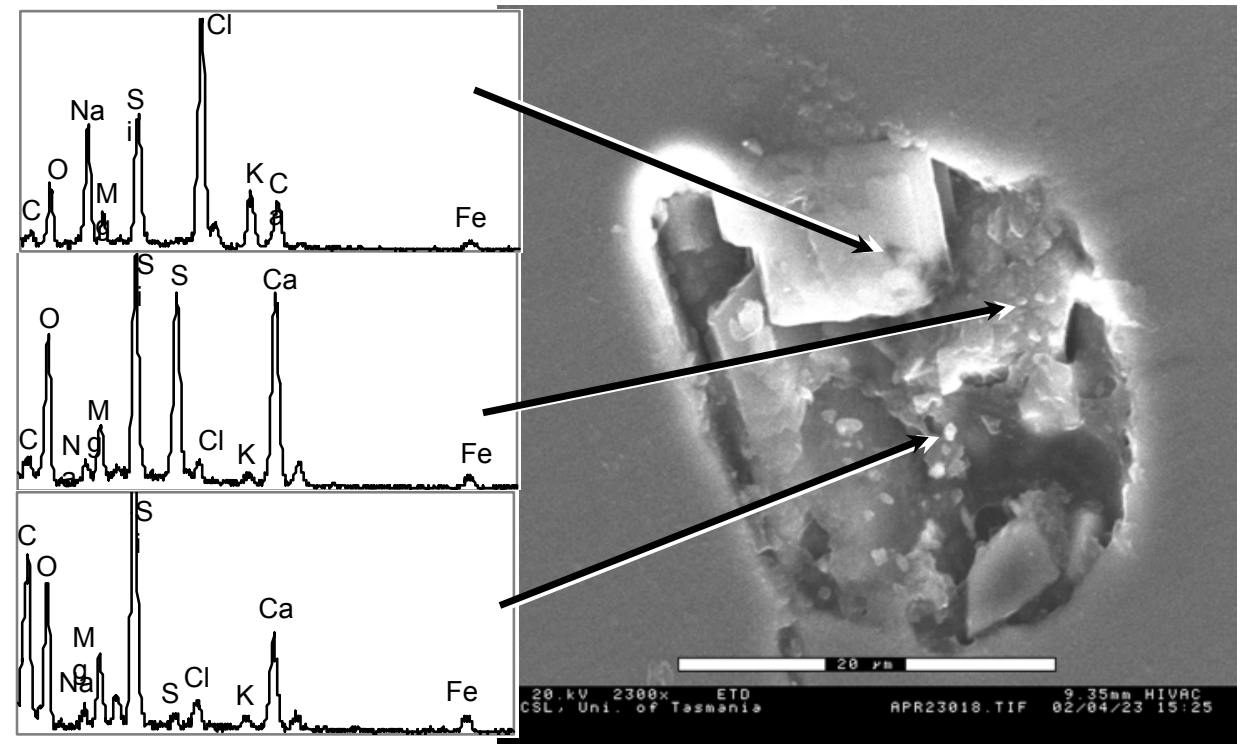

Fig. 9. Scanning electron photomicrographs and EDS spectra of phases in exposed salt melt inclusion in clinopyroxene from the Balut dyke, Didipio intrusive. Note that the sample is not carbon coated, and elevated abundances of $\mathrm{Si}, \mathrm{Mg}, \mathrm{Fe}$ and partly $\mathrm{Ca}$ in spectra are from host clinopyroxene

shows a secondary electron image of the exposed salt melt inclusion in clinopyroxene from the Balut dyke together with X-ray spectra obtained by EDS of some daughter phases $(\mathrm{Na}-\mathrm{K} \pm \mathrm{Ca}$ chlorides, $\mathrm{Ca}( \pm \mathrm{Na}+\mathrm{K})$ sulphates and possibly carbonates) present in this inclusion. Large volume of voids in this inclusion (and other exposed salt melt inclusions) was formerly occupied by an aqueous solution and vapour.

\section{Laser Raman spectroscopy}

Laser Raman spectroscopy is a non-destructive, high spatial resolution (down to 1 $\mu \mathrm{m})$ technique that can be used for the in situ analysis of individual daughter phases in unexposed salt melt and fluid inclusions within transparent host minerals. The Raman spectrum arises from inelastically scattered light resulting from the interaction of a monochromatic laser beam with the sample, which may be either a solid, liquid or a gas. It does not provide specific elemental information, but the Raman frequencies correspond to the vibrational modes of the sample, which means that it can provide important information on the molecular or crystalline structure of the sample. Furthermore, the narrowness of the Raman peaks and the common lack of overtones or combination bands means that the spectra of individual components are easier to identify as their bands can be separated from those of the host mineral. 
The technique is well suited to the study of covalently bonded compounds and has proven particularly useful, in this study, for identifying carbonate, sulphate and sulphide minerals, which have their principle Raman bands in different regions of the spectrum. It can also detect graphite/carbon in various states of crystallinity and both free and crystalline water. Unfortunately, minerals with strongly ionic character have only weak Raman spectra, or no spectra at all. Therefore, laser Raman spectroscopy cannot provide any information on the chloride salts, which are present in salt melt inclusions.

\section{Laser ablation inductively coupled plasma-mass spectrometry (LA-ICPMS)}

LA-ICPMS is a fast developing technique in fluid and melt inclusion research (e.g., Kamenetsky et al., 1997; Taylor et al., 1997; Halter et al., 2002). This method can be used in analysis of unexposed inclusions, and the advantages are very high sensitivity of modern mass spectrometers (detection limits are better than a few ppm) and short acquisition times. However, the technique has the disadvantage that it is destructive of the sample. Currently this technique may produce element concentration ratios for salt melt and fluid inclusions, but it requires one of the measured elements to have been accurately quantified by some other method prior to LA-ICPMS in order to calculate absolute concentrations.

\section{Proton-induced X-ray emission (PIXE)}

The PIXE technique, especially as implemented using the CSIRO-GEMOC Nuclear Microprobe (North Ryde, Australia; see Ryan et al., 2001a;b), is an ideal tool for high spatial resolution analytical studies of melt inclusions. It is capable of simultaneous multi-element analysis of most of the periodic table, and can be applied to unexposed inclusions. This technology uses a high-energy proton beam $(3 \mathrm{MeV})$ focussed to 1.3 $\mu \mathrm{m}$ diameter to penetrate the host mineral and excite characteristic X-rays and gammarays from elements within an inclusion. The beam is raster scanned across the sample, and the emitted X-rays are detected and used to create an element concentration map for each element in the sample. The element concentrations are calculated for individual phases accounting for sample geometry, density and depth below surface. Detection limit can be around $20 \mathrm{ppm}$, with accuracy for saturated aqueous fluids estimated at $30 \%$. This technique is "standardless" in that no prior analysis is needed to normalise the data (as with LA-ICPMS), which is an enormous benefit when analysing unexposed salt melt inclusions. Also importantly, the technique is non-destructive, although interaction with the high-energy particles may cause some phases to nucleate, or change shape or colour (Kamenetsky et al., 2002b).

Examples of PIXE element maps for a melt inclusion comprising immiscible phases is shown on Fig. 10 in order to demonstrate preferential partitioning of volatile (e.g., $\mathrm{Cl}$, $\mathrm{S}$ ) and metallic (e.g., $\mathrm{Cu}, \mathrm{Zn}, \mathrm{Pb}$ ) elements into non-silicate melts over the silicate glass. 


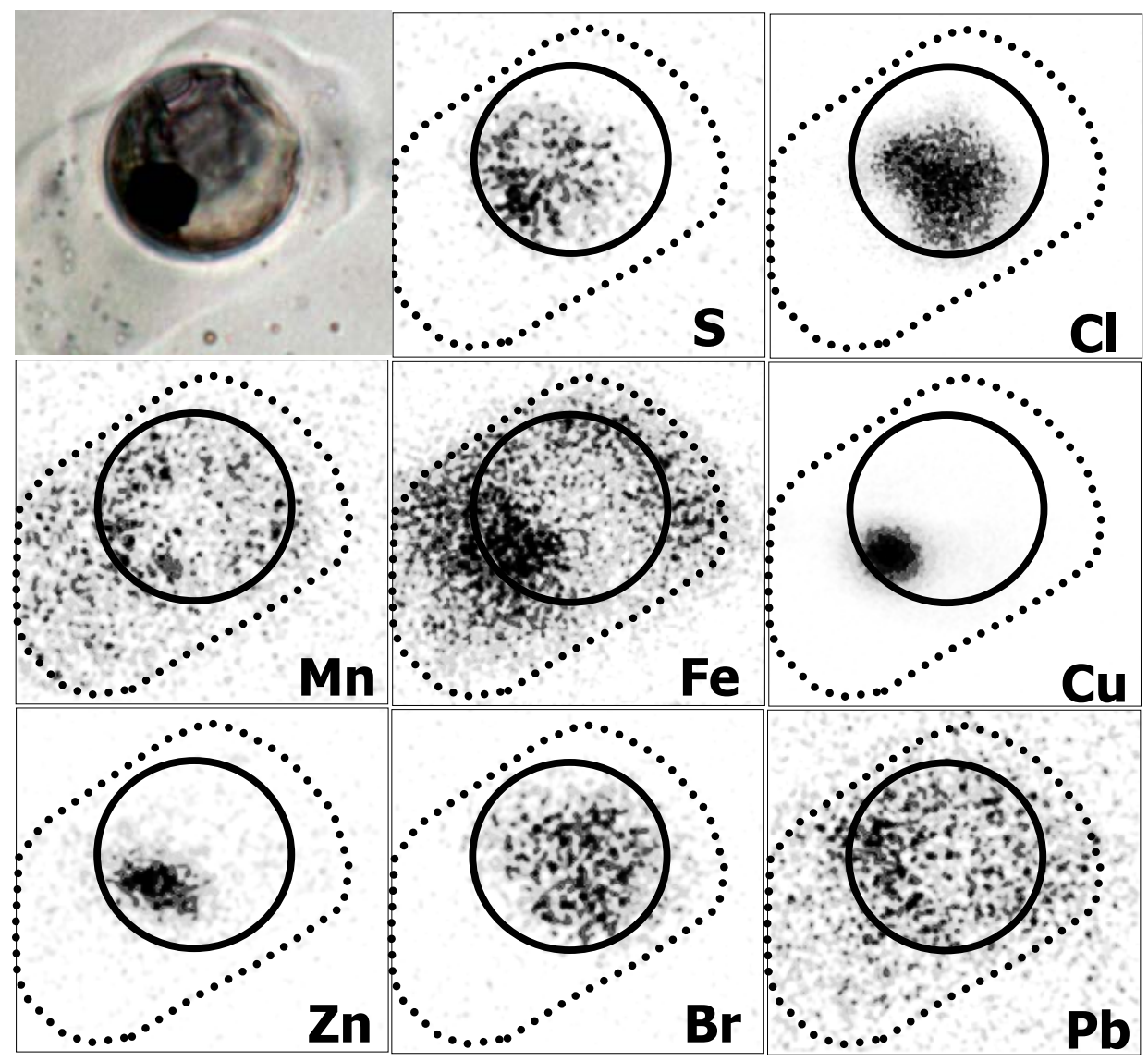

Fig. 10. Optical images and PIXE element maps of a silicate - salt - sulphide melt inclusion in K-feldspar from the Ventotene felsic xenolith (see also Fig. 8) Analysis was done using the new CSIRO-GEMOC Nuclear Microprobe (Ryan et al., 2001a;b). Intensity scale (from white to black) in each element image is normalised to its own maximum. Outlines on element maps mark boundaries of silicate glass and salt globule.

\section{CONCLUSIONS}

The pioneering work by Roedder and Coombs (1967) on the immiscibility between silicate melts and dense saline fluids in the Ascension Island granites was published thirty-five years ago. Since then amazingly little effort has been made by the international research community to tackle the problem of silicate - salt melt immiscibility by studying the late magmatic phases available in the form of phenocryst- 
hosted inclusions. Instead great strides were made to approach the physical and chemical parameters of immiscibility by experimental and theoretical studies. The reasons for this imbalance are not discussed here in detail, but one thing is clear - the study of natural samples of immiscible melts and fluids is time-consuming, painstaking, and more importantly requires a lot of "know how". However, the great advantage of inclusion studies is in that they directly apply to natural melts and fluids, and the use of modern microbeam analytical techniques, promoted in this paper, can put solid constraints on the element partitioning and the fate of volatile and economic elements.

\section{ACKNOWLEDGEMENTS}

We are grateful to R. Wolfe and S. Allen for donating samples for this research, D. Steele for assistance in the electron microscope studies, and S. Stephens for advice in lapidary works. Thoughtful review by M. L. Frezzotti is greatly appreciated. Special thanks to Olympus Australia Pty. Ltd., without their microscopes and camera systems our successful research into melt and fluid inclusions would not have been possible. Financial support for this project came from the Australian Research Council, Centre for Ore Deposit Research (Univeristy of Tasmania) and Russian Foundation for Basic Research (grant 01-05-64109).

\section{REFERENCES}

Andreyeva, I.A., Naumov, V.B., Kovalenko, V.I., Listratova, E.N. and Kononkova, N.N., 1995. Magmatic celestite in melt inclusions in apatite from the MushugayKhuduk alkali volcano-plutonic complex in south Mongolia. Trans. (Doklady) USSR Acad. Sci., 339A: 154-159.

Candela, P.A. and Holland, H.D., 1984. The partitioning of copper and molybdenum between silicate melts and aqueous fluids. Geochim. Cosmochim. Acta, 48: 373380.

Davidson, P. and Kamenetsky, V.S., 2001. Immiscibility and continuous melt-fluid evolution within the Rio Blanco porphyry system, Chile: Evidence from inclusions in magmatic quartz. Econ. Geol., 96: 1921-1929.

De Vivo, B. and Frezzotti, M.L., 1994. Evidence for magmatic immiscibility in Italian subvolcanic systems. In: B. de Vivo and M.L. Frezzotti (Eds), Fluid inclusions in minerals: methods and applications. Short course of the working group IMA. Virginia Tech., Pontignano-Siena, pp. 345-362.

De Vivo, B., Frezzotti, M.L. and Lima, A., 1993. Immiscibility in magmatic differentiation and fluid evolution in granitoid xenoliths at Pantelleria: Fluid inclusions evidence. Acta Vulcanol., 3: 195-202.

De Vivo, B., Torok, K., Ayuso, R.A., Lima, A. and Lirer, L., 1995. Fluid inclusion evidence for magmatic silicate/saline $/ \mathrm{CO}_{2}$ immiscibility and geochemistry of alkaline xenoliths from Ventotene Island, Italy. Geochim. Cosmochim. Acta, 59: 2941-2953. 
Frezzotti, M.L., 1992. Magmatic immiscibility and fluid phase evolution in the Mount Genis granite (southeastern Sardinia, Italy). Geochim. Cosmochim. Acta, 56: 21-33.

Frezzotti, M.L., 2001. Silicate-melt inclusions in magmatic rocks: applications to petrology. Lithos, 55: 273-299.

Fulignati, P., Kamenetsky, V.S., Marianelli, P., Sbrana, A. and Mernagh, T.P., 2001. Melt inclusion record of immiscibility between silicate, hydrosaline and carbonate melts: Applications to skarn genesis at Mount Vesuvius. Geology, 29: 1043-1046.

Halter, W.E., Pettke, T., Heinrich, C.A. and Rothen-Rutishauser, B., 2002. Major to trace element analysis of melt inclusions by laser-ablation ICP-MS: methods of quantification. Chem. Geol., 183: 63-86.

Harris, C., 1986. A quantitative study of magmatic inclusions in the plutonic ejecta of Ascension Island. J. Petrol., 27: 251-276.

Kamenetsky, V.S., Binns, R.A., Gemmell, J.B., Crawford, A.J., Mernagh, T.P., Maas, R. and Steele, D., 2001. Parental basaltic melts and fluids in eastern Manus backarc basin: Implications for hydrothermal mineralisation. Earth Planet. Sci. Lett., 184: 685-702.

Kamenetsky, V.S., Crawford, A.J., Eggins, S.M. and Mühe, R., 1997. Phenocrysts and melt inclusion chemistry of near-axis seamounts, Valu Fa Ridge, Lau Basin: insight into mantle wedge melting and the addition of subduction components. Earth Planet. Sci. Lett., 151: 205-223.

Kamenetsky, V.S., Davidson, P., Mernagh, T.P., Crawford, A.J., Gemmell, J.B., Portnyagin, M.V. and Shinjo, R., 2002a. Fluid bubbles in melt inclusions and pillow-rim glasses: high-temperature precursors to hydrothermal fluids? Chem. Geol., 183: 349-364.

Kamenetsky, V.S., Morrow, N. and McPhie, J., 2000. Origin of high-Si dacite from rhyolitic melt: evidence from melt inclusions in mingled lavas of the $1.6 \mathrm{Ga}$ Gawler Range Volcanics, South Australia. Mineral. Petrol., 69: 183-195.

Kamenetsky, V.S., van Achterbergh, E., Ryan, C.G., Naumov, V.B., Mernagh, T.P. and Davidson, P., 2002b. Extreme chemical heterogeneity of granite-derived hydrothermal fluids: An example from inclusions in a single crystal of miarolitic quartz. Geology, 30: 459-462.

Kamenetsky, V.S., Wolfe, R.C., Eggins, S.M., Mernagh, T.P. and Bastrakov, E., 1999. Volatile exsolution at the Dinkidi $\mathrm{Cu}-\mathrm{Au}$ porphyry deposit, Philippines: A meltinclusion record of the initial ore-forming process. Geology, 27: 691-694.

Lowenstern, J.B., 1993. Evidence for a copper-bearing fluid in magma erupted at the Valley of Ten Thousand Smokes, Alaska. Contrib. Mineral. Petrol., 114: 409-421.

Lowenstern, J.B., 1995. Applications of silicate-melt inclusions to the study of magmatic volatiles. In: J.F.H. Thompson (Ed), Magmas, fluids, and ore deposits. Mineralogical Association of Canada Short Course Series, pp. 71-99.

Lowenstern, J.B., Mahood, G.A., Rivers, M.L. and Sutton, S.R., 1991. Evidence for extreme partitioning of copper into a magmatic vapor phase. Science, 252: 14051409. 
Naumov, V.B. and Sokolov, A.L., 1981. Genetic correlation of granites and the Industrialnoe tin ore deposits according to fluid inclusions data. Geol. Ore Depos., 4: 74-80.

Naumov, V.B., Solovova, I.P., Kovalenker, V.A., Rusinov, V.L. and Kononkova, N.N., 1990. Crystallization conditions and compositions of silicate and salt melts of the volcanoplutonic complex in the Angren area, Soviet Central Asia. Trans. (Doklady) USSR Acad. Sci., 312: 199-202.

Prokofiev, V., Kamenetsky, V.S., Kovalenker, V., Bodon, S.B. and Jelen, S., 1999. Evolution of magmatic fluids at Banska Stiavnica precious and base metal deposit, Slovakia -- Evidence from melt and fluid inclusions. Econ. Geol., 94: 949-956.

Reyf, F.G., 1997. Direct evolution of W-rich brines from crystallizing melt within the Mariktkan granite pluton, west Transbaikalia. Mineralium Deposita, 32: 475-490.

Reyf, F.G. and Bazheyev, Y.D., 1977. Magmatic chloride solutions and tungsten mineralizations. Geochem. Inter., 14: 45-51.

Roedder, E., 1979. Fluid inclusions as samples of ore fluids. In: H.L. Barnes (Ed), Geochemistry of Hydrothermal Ore Deposits. Wiley \& Sons, New York, NY, pp. 684-737.

Roedder, E., 1992. Fluid inclusion evidence for immiscibility in magmatic differentiation. Geochim. Cosmochim. Acta, 56: 5-20.

Roedder, E. and Coombs, D.S., 1967. Immiscibility in granitic melts, indicated by fluid inclusions in ejected granitic blocks of Ascension Island. J. Petrol., 8: 417-451.

Ryan, C.G., McInnes, B.M., Williams, P.J., Dong, G., Win, T.T. and Yeats, C.J., 2001a. Imaging fluid inclusion content using the new CSIRO-GEMOC Nuclear Microprobe. Nuclear Instruments \& Methods in Physics Research Sect. B, 181: 570577.

Ryan, C.G., van Achterbergh, E., Griffin, W.L., Pearson, N.J., O'Reilly, S.Y. and Kivi, K., 2001b. Nuclear microprobe analysis of melt inclusions in minerals: Windows on metasomatic processes in the Earth's mantle. Nuclear Instruments \& Methods in Physics Research Sect. B, 181: 578-585.

Shinohara, H., 1994. Exsolution of immiscible vapor and liquid phases from a crystallizing silicate melt: Implications for chlorine and metal transport. Geochim. Cosmochim. Acta, 58: 5215-5221.

Solovova, I.P., Girnis, A.V., Guzhova, A.V. and Naumov, V.B., 1992. Magmatic salt inclusions in minerals from eastern Pamirs alkaline basalts. Geokhimiya, 1: 68-77.

Solovova, I.P., Girnis, A.V., Naumov, V.B., Kovalenko, V.I. and Guzhova, A.V., 1991. Mechanism of degassing of silicic magmas: formation of two fluid phases during pantellerite crystallisation, Pantelleria. Trans. (Doklady) USSR Acad. Sci., 320: 982-985.

Taylor, R.P., Jackson, S.E., Longerich, H.P. and Webster, J.D., 1997. In situ traceelement analysis of individual silicate melt inclusions by laser ablation microprobe inductively coupled plasma-mass spectrometry (LAM-ICP-MS). Geochim. Cosmochim. Acta, 61: 2559-2567. 
Thomas, R., Webster, J.D. and Heinrich, W., 2000. Melt inclusions in pegmatite quartz: Complete miscibility between silicate melts and hydrous fluids at low pressure. Contrib. Mineral. Petrol., 139: 394-401.

Tsareva, G.M., Kovalenko, V.I., Tsepin, A.I. and Naumov, V.B., 1991. Villiaumite in natural acid agpaitic magmas and its crystallization conditions (from the data of the study of melt inclusion). Doklady Akad. Nauk SSSR, 319: 1198-1201 (in Russian).

Webster, J.D., 1997. Exsolution of magmatic volatile phases from Cl-enriched mineralizing granitic magmas and implications for ore metal transport. Geochim. Cosmochim. Acta, 61: 1017-1029.

Yang, K. and Bodnar, R.J., 1994. Magmatic-hydrothermal evolution in the "bottoms" of porphyry copper systems: evidence from silicate melt and aqueous fluid inclusions in granitoid intrusions in the Gyeongsang Basin, South Korea. Inter. Geol. Rev., 36: 608-628.

Yang, K.H. and Scott, S.D., 1996. Possible contribution of a metal-rich magmatic fluid to a sea-floor hydrothermal system. Nature, 383: 420-423. 